\title{
Indo-Pasifik dalam perspektif geopolitik dan geostrategi
}

\author{
Rodon Pedrason*) \\ Universitas Pertahanan, Bogor, Indonesia
}

\begin{tabular}{l}
\hline Article Info \\
\hline Article history: \\
Received Mar $20^{\text {th }}, 2021$ \\
Revised Apr $07^{\text {th }}, 2021$ \\
Accepted May $05^{\text {th }}, 2021$ \\
\hline
\end{tabular}

\section{Keyword:}

Geopolitical interests Geostrategic policy Indo-pacific

\begin{abstract}
Indo-Pacific cannot be interpreted as a form of integration based on a region or regional areas such as Asia, or Southeast Asia, and Europe, which is based on the geographical shape of the region. The Indo-Pacific emerged as part of a geopolitical and geostrategic study based on competition patterns and state perspectives and behavior based on a broader scope of maritime interests. Indo-Pacific analysis as an object from a geopolitical and geostrategic perspective does not refer to national or regional coverage but to the global area and level. Therefore, the Indo-Pacific analysis used document analysis. In document analysis, this study combines the analysis of three primary data and 50 secondary data from national journals and international journals. In this analysis more directed at the strategic meaning of each country towards the Indo-Pacific strategic value which is then related to the maritime interests of each actor. This study describes the struggles of interests in the framework of competition through geopolitical policies and geostrategy, especially by countries that have influence. Global or the ability to shape political and security structures in the Indo-Pacific.
\end{abstract}

C 2021 The Authors. Published by IICET.

This is an open access article under the CC BY-NC-SA license

(https://creativecommons.org/licenses/by-nc-sa/4.0)

\section{Corresponding Author:}

Rodon Pedrason,

Universitas Pertahanan, Bogor

Email: rodon.pedrason@idu.ac.id

\section{Pendahuluan}

Menurut Scott (2019) dalam beberapa tahun terakhir istilah "Indo-Pasifik" semakin banyak digunakan dalam diskusi strategis yang beredar di Australia, Prancis, India, Indonesia, Jepang, dan Amerika Serikat. Istilah ini melibatkan Samudra Hindia dan Samudra Pasifik sebagai satu zona maritim yang membentuk kebijakan luar negeri, pertahanan, dan ekonomi yang sesuai. Pemaknaan wilayah Indo-Pasifik bukan dianggap atau mengacu pada wilayah regional yang terbentuk oleh integrasi kawasan regional, seperti halnya Asia Tenggara, atau Asia, dan Eropa (Medcalf, 2014). Berdasarkan hasil penelitian Kitaoka (2019) menunjukkan bahwa IndoPasifik merupakan perkembangan isu baru di politik internasional. Disamping itu, Indo-Pasifik juga mengacu pada konstruksi tatanan keamanan yang mengedepankan kepentingan maritim. Luas wilayah dan pentingnya konektifitas yang menjamin keamanan di laut serta aktifitas ekonomi setiap negara yang dipengaruhi oleh kestabilan dan keamanan maritim menjadi pondasi pemikiran yang melatarbelakangi munculnya istilah IndoPasifik sebagai sebuah "kawasan" baru dalam dinamika politik dan keamanan global(Simón, 2013). Tetapi perlu juga dicatat bahwa Indo-Pasifik memainkan hampir seluruhnya sebagai konstruksi maritim daripada kontinental(Yanuarti, Indri. Wibisono, Makarim. Midhio \& Wayan, 2020). Oleh sebab itu, negara yang terlibat terus bertambah dalam konstruksi Indo-Pasifik. Mereka harus mengatasi masalah koordinasi dan pembagian beban jika konsep kebijakan luar negerinya ingin memiliki posisi strategis. Gagasan Indo-Pasifik tidak sepenuhnya baru, meskipun tentu telah menerima banyak perhatian dalam beberapa tahun terakhir 
(Montratama, 2016). Perdana Menteri Jepang Shinzo Abe mempromosikan konsep Indo-Pasifik bersama Parlemen India pada 2007. Poin utama konsep tersebut terletak pada pertemuan dua lautan yang mempengaruhi dinamika kebebasan dan kemakmuran. Selain itu, Mantan Perdana Menteri India Manmohan Singh, saat berpidato di hadapan rekan-rekannya di Asia Timur di KTT Peringatan India-ASEAN pada 2012, mencatat bahwa India mencari masa depan yang "saling terkait" dengan negara tersebut, yang "stabil, aman dan sejahtera" di wilayah Indo-Pasifik yang memiliki pengaruh sangat penting (Atmaja, 2015).

Asia memainkan peran yang semakin kritis dalam urusan geopolitik dan geoekonomi global, Samudra Hindia dan Pasifik telah menjadi tulang punggung perdagangan yang menggerakkan perekonomian Asia (Al Syahrin, 2018). Jaringan perdagangan dalam dua samudera ini menghubungkan Asia, Amerika Utara dan Selatan, Afrika, Eropa, dan Timur Tengah (Saeed, 2017). Perairan di wilayah Indo-Pasifik mewakili arena yang semakin kritis untuk geopolitik maritim, keamanan, perdagangan, dan tindakan kebijakan lingkunganisu-isu yang telah mengubah kawasan ini menjadi persimpangan utama hubungan internasional di mana Samudra Hindia dan Pasifik barat disatukan oleh arus sumber daya alam, rantai pasokan global, dan jaringan distribusi internasional(Ramadhan, 2018). Pada saat yang sama, negara-negara pesisir Indo-Pasifik menghadapi kebijakan dan tantangan tata kelola yang signifikan dari berbagai sumber, termasuk sengketa wilayah dan persaingan di antara kekuatan angkatan laut, perebutan infrastruktur dan sumber daya kelautan dan pesisir, pembajakan dan perdagangan gelap di laut terbuka (Michel \& Passarelli, 2014).

Adaptasi setiap negara pada pentingnya sustainable atau keberlanjutan kepentingan di wilayah maritim menjadi variabel yang mempengaruhi negara dalam menentukan arah kebijakan luar negeri ke Indo-Pasifik yang sesuai dengan kepentingan negara di wilayah maritim (Saputra \& Sudirman, 2020). Ketika negara mempertimbangkan situasi geopolitik dan mewujudkan geostrategi berdasarkan situasi geopolitik - yaitu, ketika negara mengendalikan pusat sumber daya dan jalur komunikasi - negara meningkatkan dan mempertahankan posisi kekuasaan mereka (Rogers, 2013). Ketika sebuah negara gagal, atau memilih untuk tidak, memperluas kontrolnya atas sumber daya dan rute, negara-negara lain cenderung mengisi kekosongan. Dengan kata lain, kontrol eksklusif atas rute dan sumber daya adalah sumber kekuatan yang tidak dapat digantikan oleh "pasar" (Grygiel, 2006). Sumber daya dan jalur komunikasi menjadi variabel yang dibutuhkan negara dalam memenuhi kepentingan nasional melalui perilaku ekspansif untuk mengontrol nilai strategis dari kondisi geografis tersebut(Rani, 2012). Pada tingkat kebijakan luar negeri, geografi adalah realitas geopolitik yang direspon negara dengan merumuskan dan mengejar geostrategi (Pan, 2014). Negaranegara yang melindungi wilayah asal mereka (atau, sebagai proxy, memiliki perbatasan yang stabil), kemudian mengejar kontrol sumber daya, dan yang mengamankan rute yang menghubungkan mereka dengan pusat sumber daya, meningkatkan dan mempertahankan kekuatan relatif mereka (Grygiel, 2006). Batas wilayah negara mendorong negara untuk melewati perbatasan untuk menjaga keamanan dan kontrol tata letak rute perdagangan atau kondisi geografis seperti daratan atau laut. Selain itu, keterbatasan sumber daya dalam negeri, mendorong negara untuk memenuhi kepentingan tersebut dengan mengeksplorasi dan mengeksploitasi berbagai sumber daya di luar negara (Fajrina et al., 2020).

Menurut Stephen Walt (1992) dalam (Ali, Prakoso, \& Sianturi, 2020) memandang geografi dengan cara minimalis dengan menegaskan bahwa jarak berdampak pada persepsi ancaman. Art dan Jervis (2007) menunjukkan kompleksitas geografi, yang mempengaruhi kemungkinan perang dengan menghadirkan hambatan bagi proyeksi kekuatan militer. Secara umum, kedua mazhab pemikiran menekankan pada keadaan geografis sebagai fakta alamiah yang tidak dapat berubah yang mempengaruhi persepsi atau perhitungan negarawan. Karena itu, dampak lingkungan sebagian besar terbatas pada bidang psikologis. Geografi adalah variabel intervening yang mempengaruhi persepsi negarawan yang berasal dari sumber lain (kekuasaan, masalah keamanan, dll.); geografi memediasi pengaruh kekuasaan pada hasil akhir, apakah kebijakan luar negeri suatu negara atau sistem internasional. Dengan demikian, sejalan dengan Grygiel (2006) geografi mengurangi atau memperburuk efek anarki. Kondisi geopolitik dan geostrategi Indonesia yang sangat menguntungkan ini, tentu saja merupakan nilai tambah bagi Indonesia dalam merencanakan sosok keamanan nasional dan pertahanannya termasuk di dalamnya adalah strategi dan postur pertahanan agar dapat memainkan peran sentral di kawasan Asia Tenggara dan Asia Timur. Untuk itulah penelitian ini menganalisis lebih mendalam terkait Oleh sebab itu, apakah indonesia sudah menggunakan geopolitik dan geostrategi dengan tepat berdasarkan riset-riset yang telah ada.

\section{Metode}

Dalam melakukan analisis terkait Indo-Pasifik dalam Perspektif Geopolitik dan Geostrategi menggunakan pendekatan kualitatif berbasis dokumen (Bakry, 2016). Menurut Bowen (2009) analisis dokumen adalah prosedur sistematis untuk mengevaluasi dokumen baik materi cetak maupun elektronik (berbasis komputer 
dan ditransmisikan melalui Internet). Seperti metode lain dalam penelitian kualitatif, analisis dokumen mengharuskan data diperiksa dan diinterpretasikan untuk mendapatkan makna, memperoleh pemahaman, dan mengembangkan pengetahuan empiris. Dalam analisis dokumen, penelitian ini menggabungkan analisis data primer dan data sekunder. Dokumen yang digunakan berjumlah tiga data primer yang didapatkan melalui dokumen resmi yang dirilis oleh pemerintah yaitu perjanjian bilateral dan multilateral yang didapat dari instansi terkait seperti kantor Kementerian Koordinator Bidang Politik, Hukum dan Keamanan, serta Buku Putih Pertahanan Republik Indonesia. Data primer lainnya didapatkan dari laman resmi Kementerian Pertahanan Republik Indonesia. Untuk data sekunder diperoleh melalui kajian literatur yang telah ada dan memiliki kontribusi dalam penelitian ini yaitu buku, jurnal, dokumen, dan surat kabar yang sudah dilakukan triangulasi data sehingga dapat digunakan untuk mendukung penelitian (Bakry, 2016). Jumlah buku yang di analisis berjumlah dua dan berhubungan dengan geopolitik. Sedangkan untuk jurnal peneliti melakukan analisis sebanyak 25 artikel jurnal Internasional dan 25 artikel jurnal nasional yang berhubungan dengan geopolitik serta geostrategis. Sumber pencarian jurnal yang digunakan adalah Taylor and Francis, Garuda Dikti, dan Google Scholar.

\section{Hasil dan Pembahasan}

\section{Nilai Strategis Indo-Pasifik}

Berdasarkan hasil analisis dokumen yang dilakukan Nashir, Komeini, dan Rosdiana(2021) menunjukkan bahwa Indo-Pasifik merupakan rumah bagi 10 dari 20 ekonomi dengan pertumbuhan tercepat. Sehingga, Indo-Pasifik saat ini mengandung lebih dari sepertiga PDB global. Oleh sebab itu, Indo-Pasifik diproyeksikan mampu menyumbang lebih dari 55 persen dari PDB global pada tahun 2050. Hal ini terjadi dikarenakan sebagian besar disebabkan oleh kelas menengah yang tumbuh. Pendatang kelas menengah berikutnya akan datang dari Indo-Pasifik dengan jumlah 87 persen dari satu miliar. Lebih tepatnya dari kelas menengah dunia akan tinggal di Indo-Pasifik yang akan mewakili jumlah daya beli tak tertandingi. Singkatnya, pasar potensial dan prospek ekonomi menghadirkan peluang yang semua bisa mendapat manfaat selama semua negara, besar dan kecil, bekerja sama (Davidson, 2019). Permasalahan yang berkembang adalah masalah keamanan yang bersifat non-tradisional di laut dan samudera. Disisi lain, perbedaan antara negara pengguna pesisir dan maritim yang melibatkan operasi navigasi dan militer mewakili beberapa masalah mendesak yang mempengaruhi kawasan ini (Rahman, 2011).

Pada tingkat kebijakan luar negeri, geografi adalah realitas geopolitik yang direspon negara dengan merumuskan dan mengejar geostrategi (Fathun, 2017). Negara-negara yang melindungi wilayah asal mereka kemudian mengejar kontrol sumber daya. Selain itu, mereka juga melakukan pengamanan rute yang menghubungkan dengan pusat sumber daya, meningkatkan dan mempertahankan kekuatan relatif mereka (Grygiel, 2006). Batas wilayah negara mendorong negara untuk melewati perbatasan untuk menjaga keamanan dan kontrol tata letak rute perdagangan atau kondisi geografis seperti daratan atau laut (Radityo, Rara, Amelia, \& Efraim, 2019). Selain itu, keterbatasan sumber daya dalam negeri, mendorong negara untuk memenuhi kepentingan tersebut dengan mengeksplorasi dan mengeksploitasi berbagai sumber daya di luar negara. Geografi bukan lagi lingkungan yang mempengaruhi tindakan manusia, tetapi sebuah teater bagi manusia dan negara bertindak sesuai dengan kepentingan yang mereka kejar (Taher, 2017). Disamping itu, sistem internasional adalah seperangkat aturan atau pola perilaku yang kaku dan memaksa kekuatan untuk menyeimbangkan kekuatan lain. Di sisi lain, konteks interaksi kerjasama, kompetisi dan konflik antar negara, terutama negara-negara besar dengan kepentingan global, seperti AS, Cina, Jepang dan India. Oleh karena itu, mereka menjadi pemain utama yang membentuk atmosfer interaksi antar negara (S. Utami, Sumertha, \& Pedrason, 2019). Keterlibatan negara-negara tersebut memberikan porsi lebih besar dibandingkan negaranegara lain dalam membentuk struktur politik dan keamanan internasional yang tersaji di Indo-Pasifik (Vandini, Pedrason, \& Mundayat, 2018). Berdasarkan hasil penelitian Michel dan Passarelli (2014) beragam perspektif strategis tentang pentingnya Indo-Pasifik telah dikembangkan oleh aktor regional, termasuk Amerika Serikat, India, Cina, Australia, Indonesia, dan Jepang. Indo-pasifik ini menjadi penting karena telah didorong oleh pertumbuhan ekonomi Cina yang dramatis, peningkatan perdagangan dan produktivitas India yang terus-menerus, serta meningkatnya ekspor minyak mentah dari Timur Tengah ke Asia (Yanuarti, Indri. Wibisono, Makarim. Midhio \& Wayan, 2020). 


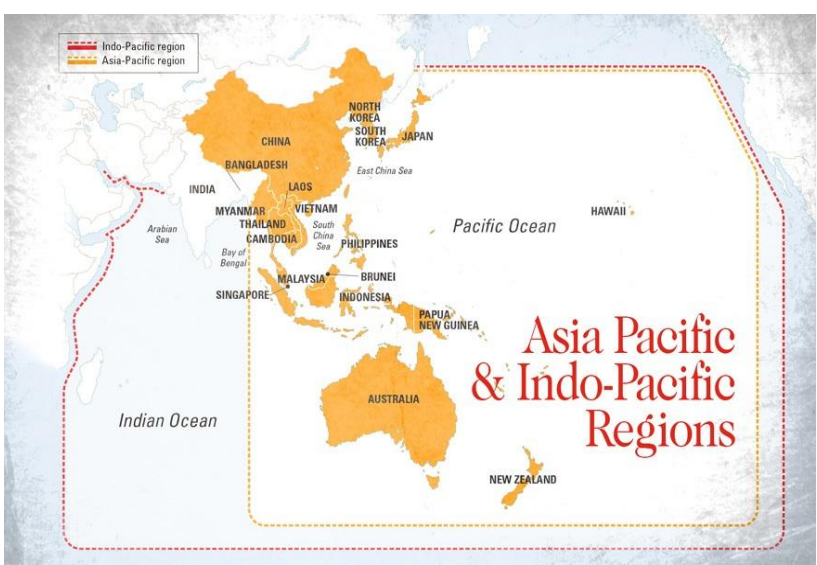

Gambar 1. Tata Letak dan Nilai Strategis Indo-Pasifik bagi Negara

(Sumber: Gopalaswamy (2013))

Samudra Hindia memiliki empat dari enam chokepoint utama maritim dan berfungsi sebagai jalan raya super maritim untuk sumber daya energi yang dibutuhkan yang menggerakkan perekonomian terbesar dunia (Rustam, 2016). Hampir 68 persen minyak India, 80 persen minyak Cina, dan 25 persen minyak AS dikirim dari wilayah Samudera Hindia. Meskipun penting dalam haknya sendiri, perbatasan Timur Samudera Hindia dengan Pasifik semakin tidak relevan karena pergeseran terjadi dalam keseimbangan global dan Kawasan Indo-Pasifik tumbuh dalam signifikansi geostrategis (Simón, 2013). Kepentingan negara dan perkembangan teknologi merubah wilayah geografis tertentu sebagai wilayah yang mengalami peningkatan nilai strategis, seperti perairan internasional sebagai jalur transportasi perdagangan dunia. Kondisi itu membuat setiap negara di dunia bergantung pada kepentingan keamanan jalur transportasi untuk menjamin berbagai kegiatan ekonomi dan keamanan negara. Hal itu menjelaskan bahwa wilayah perairan menjadi objek kebijakan geopolitik dimana setiap negara cenderung berkompetisi dan bahkan mengarah pada tensi konflik ketika terdapat kepentingan yang saling berbenturan (Harris, Prakoso, \& Sianturi, 2019). Terlebih lagi, ketika wilayah perairan dapat dikontrol, maka kekuatan negara terhadap negara lain akan meningkat. Kontrol wilayah menjadi variabel yang memungkinkan negara untuk mempengaruhi negara lain dan membatasi negara lain dalam meningkatkan kekuatan atau mencapai kepentingan (Kurniawan \& Puspitasari, 2017).

Kepentingan Geopolitik dan Kebijakan Geostrategi di Indo-Pasifik

Ketika negara dihadapkan pada kepentingan nasional, maka negara perlu melakukan kalkulasi strategi mengingat kepentingan setiap negara cenderung berbenturan dengan kepentingan nasional negara lain (Utami \& Kurniawati, 2017). Dengan kata lain, struggle of interests akan menjadi tema besar dalam interaksi antar negara, selain kerjasama yang bersifat parsial. Dalam istilah sederhana, strategi di semua tingkatan adalah kalkulasi tujuan, konsep, dan sumber daya dalam batas risiko yang dapat diterima untuk menciptakan hasil yang lebih menguntungkan. Pada tingkat ini, strategi adalah seni dan ilmu untuk mengembangkan dan menggunakan kekuatan politik, ekonomi, sosial-psikologis, dan militer negara sesuai dengan pedoman kebijakan untuk menciptakan efek yang melindungi atau memajukan kepentingan nasional relatif terhadap negara lain, aktor, atau keadaan (Yarger, 2006). Secara konseptual, teori strategi mengedukasi pikiran ahli strategi. Hal ini untuk membantu mendisiplinkan pemikiran strategi menghadapi kompleksitas dan volatilitas lingkungan strategis dan perubahan dan kontinuitas, masalah, peluang, dan ancaman yang melekat padanya (Harris, 2012). Memahami lingkungan strategis berarti memahami realitas dan hubungan lingkungan di sekitarnya dengan kepentingan yang diperlukan negara (Rogers, 2013). Dengan begitu, kalkulasi dan penerapan strategi sesuai dengan kondisi lingkungan yang mempengaruhi negara. Hal tersebut merupakan pemahaman para pengambil kebijakan terhadap perkembangan lingkungan strategis memiliki dampak strategis sekaligus vital bagi keberlangsungan negara dalam memenuhi kepentingan nasionalnya.

Keseimbangan strategis Amerika Serikat di Asia-Pasifik telah mencakup kehadiran angkatan laut yang kuat yang ditujukan untuk mengamankan beberapa kepentingan strategis (Harris, 2014). Di antara kepentingan utamanya, AS berupaya untuk menjamin kebebasan navigasi untuk energi dan perdagangan komersial, memastikan keseimbangan kekuatan yang stabil, memantau dan mencegah ancaman dari para pelaku seperti Iran dan Korea Utara, dan mengarahkan berbagai operasi keamanan maritim seperti misi kontra-teroris, kontra-perdagangan manusia, dan kontra-pembajakan. Sementara itu, Cina dan India telah berupaya untuk menyatukan antara kerjasama strategis dan hubungan kompetitif mereka. Sejumlah kepentingan ekonomi dan politik, dan jaringan interaksi bilateral dan multilateral yang meluas di kawasan ini, 
telah mengubah persepsi antara kedua raksasa Asia dan berkaitan dengan Amerika Serikat (Michel \& Passarelli, 2014).

Berdasarkan hasil penelitian Herindrasti (2019) meningkatnya aktivitas di seluruh Indo-Pasifik karena memperluas perdagangan regional dan global dalam hal barang, ide, orang, dan sumber daya telah mengangkat serangkaian tantangan keamanan maritim baru (Herindrasti, 2019). Kekhawatiran berbasis negara historis seperti kerapuhan geopolitik, kerawanan politik internal, pemberontakan internal, pemberontakan, ketegangan antar negara, keamanan jalur laut, dan perselisihan wilayah kini ditambah dengan ancaman yang meningkat dari sumber-sumber non-negara dan risiko asimetris (Jung, Lee, \& Lee, 2021). Berbagai tantangan ini menghadapi serangkaian negara yang sama berbatasan dengan wilayah ini, mulai dari negara-negara makmur dengan aturan hukum yang kuat hingga negara-negara berpenghasilan rendah dengan struktur pemerintahan yang lemah atau terfragmentasi (Davidson, 2019). Sejalan dengan Michel dan Passarelli (2014) keragaman dalam kepentingan dan kemampuan ini membebani kawasan IndoPasifik dengan ketegangan politik dan membawa serta bahaya ketidakstabilan dan konflik yang lebih besar.

Menurut Bhatt dalam (Iriawan, 2018) menunjukkan berbagai dokumen kebijakan dan pertahanan empat negara demokrasi besar seperti Australia, Jepang, dan AS, bersama dengan India. Hal ini dilakukan untuk memahami konsepsi mereka tentang Indo-Pasifik sebagai wilayah dan ancaman yang dihadapi serta kepentingan nasional. Sebagai contoh, refleksi Jepang terhadap Indo-Pasifik adalah manifestasi eksternal dari visi domestiknya, yang berorientasi pada pembangunan berdasarkan penghormatan terhadap norma dan aturan. Aspirasi ini juga tercermin dalam buku putih 2017 dengan jelas mendefinisikan Indo-Pasifik sebagai bidang utama untuk pembangunan. Bagi Australia, Asia Tenggara, sebagai bagian dari Indo-Pasifik, yang stabil dan aman adalah minat strategis yang vital (Medcalf, 2014). Pada saat yang sama, Australia mempromosikan keinginan untuk memimpin koalisi militer dan memberikan kontribusi khusus kepada koalisi militer dengan negara-negara yang memiliki kepentingan strategis bersama di kawasan ini (Iriawan, 2018). Di sisi lain, dinamika yang kompleks terjadi di kawasan Indo-Pasifik. Negara tersebut berusaha mendorong AS keluar dari Pasifik Barat. Cina sebagai salah satu kekuatan ekonomi, politik, dan militer di dunia, tidak mengizinkan Amerika Serikat dan sekutunya mendapatkan kebebasan navigasi di laut dekat China atau Laut Cina Selatan. Hal ini dikarenakan Cina menjadi salah satu wilayah strategis di kawasan Indo-Pasifik (Kartini, 2016). Nilai strategis Indo-Pasifik menjelaskan perubahan wilayah tersebut sebagai objek kebijakan luar negeri setiap negara, terutama negara-negara yang memiliki kedekatan wilayah geografis, dan negara-negara yang memiliki ambisi besar dalam menguasai wilayah-wilayah strategis di dunia (Shah, 2020).

Keterlibatan banyak negara melalui kebijakan luar negeri untuk terlibat dalam berbagai isu menyangkut wilayah Indo-Pasifik menjelaskan tidak hanya perubahan nilai strategis wilayah Indo-Pasifik, namun juga menjadi wilayah kompetisi distribusi kekuatan antar negara (Saeed, 2017). Dalam kasus kehadiran negaranegara besar di Indo-Pasifik, faktor pendorong kebijakan strategis seperti negara Amerika Serikat tidak terlepas dari kepentingan nasional negara tersebut dalam mempertahankan pengaruh global sekaligus menghadapi kebangkitan Cina dan Rusia sebagai ancaman di kawasan Indo-Pasifik. Tindakan yang dilakukan oleh Amerika Serikat telah berupaya untuk mencapai stabilitas melalui pengembangan kapasitas dan kerja sama regional, jika memungkinkan, dan pencegahan jika diperlukan(Jung et al., 2021). Tindakan peningkatan kapasitas, seperti bantuan keuangan, penyediaan aset, pelatihan dan pendidikan militer, serta skema kerja sama regional. Kerjasama tersebut dilakukan dengan kegiatan multilateral latihan, berbagi informasi, dan patroli bersama, telah dilaksanakan dalam kemitraan dengan Korea Selatan, Australia, Selandia Baru, Indonesia, Jepang, Filipina, Vietnam, serta Malaysia (Michel \& Passarelli, 2014). Interaksi antar negara yang tersaji di kawasan tersebut, salah satunya dipengaruhi oleh keterlibatan negara-negara besar yang memiliki kepentingan dan kebijakan global (Yunanto \& Samhudi, 2019). Kondisi tersebut berkonsekuensi pada dinamika lingkungan strategis, seperti dinamika wilayah maritim Indo-Pasifik yang tidak lagi didominasi oleh satu negara adidaya tetapi sedang dibentuk oleh beberapa kekuatan besar (Purnama, 2017). Oleh sebab itu, Cina dianggap oleh banyak pihak lain sebagai kekuatan yang berpotensi membuat tidak stabil (Wirth, 2018).

Oleh karena itu, tujuan strategis Cina di wilayah laut adalah untuk memastikan bahwa tidak adanya penolakan terhadap akses Cina ke laut dekat dan apa yang dianggapnya sebagai hak maritim (Nashir et al., 2021). Disisi lain, Cina memiliki motif yang sah untuk melindungi provinsi pesisir Laut Cina Selatan dan jalur laut yang menjadi sandaran seluruh negara. Sebagian besar impor energi Tiongkok dan barang-barang lainnya melewati Laut Cina Selatan dan pada tingkat yang lebih rendah, melalui Laut Cina Timur (Michel \& Passarelli, 2014). Tujuan kebijakan Cina perlu dipahami dalam konteks strategis terkait respons dari kekuatan signifikan lainnya (Yanuarti, Indri. Wibisono, Makarim. Midhio \& Wayan, 2020). Hal ini dikarenakan jika semakin lebar kesenjangan antara persepsi China dan orang lain tentang motif dan perilakunya, maka semakin besar risiko terhadap perdamaian dan stabilitas kawasan (Wirth, 2018). Oleh karena itu, bagi negara Amerika 
Serikat, Jepang, Australia, dan India, tujuan serta kebijakan Cina di kawasan Indo-Pasifik merupakan ancaman terhadap kepentingan nasional negara tersebut (Iriawan, 2018). Konteks ancaman tersebut menjelaskan perilaku Cina di kawasan tersebut menghadirkan perubahan yang mempengaruhi Amerika Serikat, Jepang, Australia, dan India dalam mengamankan kepentingan nasional(Wirth, 2018). Sehingga potensi kekerasan (violence) menjadi besar dan mempengaruhi sikap serta kebijakan dari keempat negara tersebut yang secara bersama memandang Cina sebagai ancaman (Pant \& Rej, 2018). Amerika Serikat, Jepang, Australia, dan India, melalui The QUAD dengan tegas menyatakan bahwa ancaman Cina di IndoPasifik adalah sesuatu yang nyata (Medcalf, 2014;Medcalf, 2017). Indo-Pasifik yang bebas dan terbuka menjadi pesan politik kepada Cina yang dianggap sebagai ancaman, mengingat negara tersebut, dengan tegas menekankan bahwa beberapa wilayah strategis di Indo-Pasifik sebagai kawasan kedaulatan dan kontrol Cina dalam mengeksploitasi sumber daya, serta menjadi arena kebijakan BRI (Belt Road Initiative) negara tersebut (Pedrason, 2019).

Dari perspektif Cina, Amerika Serikat memiliki kepentingan untuk membangun kerjasama strategis lebih dekat dengan sekutu regional dan mitra keamanan seperti India yang melakukan konsolidasikan supremasi strategisnya (Heiduk \& Wacker, 2020). Selain itu, sebagai opsi potensial juga melakukan pemblokiran di titiktitik utama sepanjang jalur komunikasi laut regional (SLOC) untuk mengintimidasi Cina (Saeed, 2017). Persoalan tersebut tidak terlepas dari konsep BRI yang menjadi kebijakan geopolitik Cina. Sejak lama, negara tersebut telah mengusulkan BRI pada tahun 2013 yang mencakup Jalur Ekonomi Jalur Sutra dan Jalur Sutra Maritim abad ke-21. Hal ini dilakukan untuk membangun kembali Jalur Sutra kuno dengan menghubungkan Asia Tenggara dengan Afrika dan Eropa melalui pembangunan infrastruktur/pelabuhan di negara-negara sepanjang garis pantai (Radityo et al., 2019). Karena itu, Cina telah membangun kekuatan maritim yang dirancang untuk mencapai kepentingan ekonomi dan keamanannya. Selain itu, Cina mencoba memimpin pengembangan ekonomi regional dan inter-konektivitas, melanjutkan penggelaran angkatan laut dan membangun inisiatif ekonomi di Indo-Pasifik (Huang, 2016). Sejalan dengan Saeed (2017) penempatan kapal induk dengan fasilitas teknologi modern telah dikerahkan di Pasifik, dan peningkatan kapal selam kelas kilo terbaru dengan kualitas serangan terbaik dan kapal perusak modern yang dilengkapi dengan rudal dari Rusia. Semua kekuatan militer tersebut ditujukan untuk memperkuat posisi strategis Cina di Indo-Pasifik (Mukherjee, 2016). Bentuk perimbangan kekuatan antar aktor sulit untuk dibendung. Persaingan antar negara masih memasuki fase awal kompetisi kekuatan antar negara-negara untuk meningkatkan peran mereka (Callahan, 2016). Disisi lain, kompetisi tersebut juga dilakukan untuk meningkatkan kekuatan politik dan keamanan di wilayah Indo-Pasifik. Kondisi tersebut menjelaskan perjalanan panjang arsitektur politik internasional dan keamanan global di Indo-Pasifik.

\section{Kesimpulan}

Indo-Pasifik merupakan wilayah maritim dengan tata letak yang strategis, baik sumber daya laut yang berada di bawahnya, maupun posisi strategis dalam mendukung berbagai kebijakan negara di maritim. Kondisi strategis juga tercermin pada wilayah tersebut yang menjadi bagian dari wilayah kedaulatan negara. Hal tersebut yang pada akhirnya menjelaskan kompleksitas interaksi antar negara. Terlebih lagi, kepentingan negara tidak terbatas pada eksplorasi sumber daya maritim, namun juga kontrol terhadap akses yang berkonsekuensi pada keuntungan politik dan ekonomi. Faktor kepentingan strategis tersebut yang kemudian mendorong dinamika pergeseran kekuatan yang dipengaruhi oleh berbagai kebijakan keamanan, terutama negara-negara yang memiliki kemampuan dan pengaruh dalam membentuk struktur keamanan di IndoPasifik. Distribusi kekuatan menjadi opsi yang tidak terhindarkan, baik pengerahan kekuatan militer maupun kerjasama, dan aliansi sebagai opsi-opsi yang relevan dalam menghadapi kompleksitas persaingan dalam memenuhi kepentingan strategis. Kondisi tersebut menggambarkan perspektif antar aktor (negara) dalam memandang perilaku aktor lain sebagai ancaman terhadap kepentingan strategis. Langkah perimbangan menjadi medan interaksi yang ditujukan untuk membatasi ruang gerak aktor lain sebagai bagian dari persaingan dalam meningkatkan pengaruh politik dan keamanan setiap aktor sebagai upaya untuk mencegah dominasi perilaku aktor lain yang menjadi ancaman bagi kepentingan geopolitik dan pesaing dalam kebijakan geostrategis setiap aktor negara.

\section{Referensi}

Art, Robert J., \& Jervis, Robert. (2007). International Politics: Enduring Concepts and Contemporary Issues. London: Pearson Longman.

Al Syahrin, M. N. (2018). Kebijakan Poros Maritim Jokowi dan Sinergitas Strategi Ekonomi dan Keamanan Laut Indonesia. Indonesian Perspective, 3(1), 1. https://doi.org/10.14710/ip.v3i1.20175 
Ali, I. M., Prakoso, L. Y., \& Sianturi, D. (2020). Strategi Pertahanan Laut dalam Menghadapi Ancaman Keamanan maritim di Wilayah Laut Indonesia. Strategi Pertahanan Laut, 6(2), 169-188.

Atmaja, J. T. (2015). Politik Luar Negeri Perdana Menteri Manmohan Singh terhadap Terorisme di India. Transformasi, 1(1), 55-60.

Bakry, U. S. (2016). Metode Penelitian Hubungan Internasional. Yogyakarta: Pustaka Pelajar.

Bowen, G. A. (2009). Document analysis as a qualitative research method. Qualitative Research Journal, 9(2), 27-40. https://doi.org/10.3316/QRJ0902027

Callahan, W. A. (2016). China's "Asia Dream": The Belt Road Initiative and the new regional order. Asian Journal of Comparative Politics, 1(3), 226-243. https://doi.org/10.1177/2057891116647806

Davidson, P. (2019). Introduction to the Indo-Pacific Security Challenges. Journal of Indo-Pacific Affairs, Spring.

Fajrina, Nur, Amaliana, Roziqin, Ali, Sihidi, \& Taqwa, I. (2020). Studi Geopolitik Laut China Selatan: Data Dan Analisis Media Sosial. Jurnal Kajian Lemhannas RI, 43(4), 35-47.

Fathun, L. M. (2017). Kebijakan Geopolitik Poros maritim di Era Jokowi. Jurnal Power in International Relations, 1(2), 1-29.

Grygiel, J. J. (2006). Great Powers and Geopolitical Change. Baltimore: The John Hopkins University Press.

Harris, A., Prakoso, L. Y., \& Sianturi, D. (2019). Strategi Pertahanan Laut dalam Rangka Ancaman Keamanan di Alur Laut Kepulauan Indonesia II. Strategi Pertahanan Laut, 5(1), 15-30.

Harris, B. F. (2014). United States Strategic Culture and Asia-Pacific Security. Contemporary Security Policy, 35(2), 290-309. https://doi.org/10.1080/13523260.2014.928084

Harris, L. (2012). Implications of a strategic analysis: The operational strategy of loyalist paramilitaries. Behavioral Sciences of Terrorism and Political Aggression, 4(1), 4-25. https://doi.org/10.1080/19434472.2011.631348

Heiduk, F., \& Wacker, G. (2020). From Asia-Pacific to Indo-Pacific: significance, implementation and challenges. Berlin.

Herindrasti, S. (2019). Fenomena Indo-Pasifik Dan Diplomasi Indonesia. Jurnal Asia Pacific Studies, 3(1), 43. https://doi.org/10.33541/japs.v3i1.965

Huang, Y. (2016). Understanding China's Belt \& Road Initiative: Motivation, framework and assessment. China Economic Review, 40(2016), 314-321. https://doi.org/10.1016/j.chieco.2016.07.007

Iriawan, S. (2018). Diskursus Indo-Pasifik: Hegemoni Amerika, Persaingan Strategis, Hingga Transformasi Geopolitik Kawasan. Mandala: Jurnal Hubungan Internasional, 1(2), 282-310. Retrieved from https://ejournal.upnvj.ac.id/index.php/JM/article/view/434/339

Jung, S. C., Lee, J., \& Lee, J. Y. (2021). The Indo-Pacific Strategy and US Alliance Network Expandability: Asian Middle Powers' Positions on Sino-US Geostrategic Competition in Indo-Pacific Region. Journal of Contemporary China, 30(127), 53-68. https://doi.org/10.1080/10670564.2020.1766909

Kartini, I. (2016). Kebijakan Jalur Sutra Baru Cina Dan Implikasinya Bagi Amerika Serikat. Jurnal Kajian Wilayah, 6(2), 131-147. Retrieved from http://ejournal.lipi.go.id/index.php/jkwpsdr/article/view/334

Kitaoka, S. (2019). Vision for a Free and Open Indo-Pacific. Asia-Pacific Review, 26(1), 7-17. https://doi.org/10.1080/13439006.2019.1618592

Kurniawan, D., \& Puspitasari, I. (2017). Hedging Maritim Indonesia di Tengah Persaingan Strategis IndiaChina. Indonesian Perspective, 2(2), 85. https://doi.org/10.14710/ip.v2i2.18481

Medcalf, R. (2014). In defence of the Indo-Pacific: Australia's new strategic map. Australian Journal of International Affairs, 68(4), 470-483. https://doi.org/10.1080/10357718.2014.911814

Medcalf, R. (2017). Reimagining Asia: From Asia-Pacific to Indo-Pacific. International Relations and Asia's Southern Tier, 9-28. https://doi.org/10.1007/978-981-10-3171-7_2

Michel, D., \& Passarelli, R. (2014). Sea Change: Envolving Maritime Geopolitics in The Indo-Pacific Region.

Montratama, I. (2016). The Reconstruction of Indonesia Foreign Policy amidst the 21st Century Strategic Circumstances Dynamics in Indo-Pacific. Intermestic: Journal of International Studies, 1(1), 36-61. https://doi.org/10.24198/intermestic.v1n1.4

Mukherjee, A. (2016). Maritime security in the Indo-Pacific: perspectives from China, India, and the United States. Journal of the Indian Ocean Region, 12(2), 232-233. https://doi.org/10.1080/19480881.2015.1119977

Nashir, A. K., Komeini, Y., \& Rosdiana, H. (2021). Strategic Environment, Strategist, and Strategy. Jurnal Global \& Strategis, 15(1), 103. https://doi.org/10.20473/jgs.15.1.2021.103-126

Pan, C. (2014). The "Indo-Pacific" and geopolitical anxieties about China's rise in the Asian regional order. Australian Journal of International Affairs, 68(4), 453-469. https://doi.org/10.1080/10357718.2014.884054

Pant, H. V., \& Rej, A. (2018). Is India ready for the Indo-Pacific? Washington Quarterly, 41(2), 47-61. https://doi.org/10.1080/0163660X.2018.1485403

Pedrason, R. (2019). Belt and Road Iniative: Peluang dan Tantang. Surabaya: Jakad Media Publishing.

Purnama, A. C. (2017). Gagasan Indo-Pacific Treaty: Prospek dan Masalah. Jurnal Pertahanan \& Bela Negara, 
$7(2), 85-114$.

Radityo, F., Rara, G., Amelia, I., \& Efraim, R. (2019). Geopolitik Tiongkok Di Kawasan Asia Tenggara: Jalur Perdagangan (Obor). Jurnal Asia Pacific Studies, 3(1), 84. https://doi.org/10.33541/japs.v3i1.1073

Rahman, C. (2011). The Geopolitical Context," in Mahnken, Thomas G. (ed) " Indo-Pacific Maritime Security in the 21th Century. Proceeding of an International Conference US Naval War College and Lowly Institute for International Policy.

Ramadhan, I. (2018). China's Belt Road Initiative: Dalam Pandangan Teori Geopolitik Klasik. Intermestic: Journal of International Studies, 2(2), 139. https://doi.org/10.24198/intermestic.v2n2.3

Rani, F. (2012). Strategi Pemerintah Indonesia Dalam Meningkatkan Keamanan Wilayah Perbatasan Menurut Perspektif Sosial Pembangunan. Jurnal Transnasional, 4(1), hlm. 5.

Rogers, J. (2013). European (British and French) geostrategy in the Indo-Pacific. Journal of the Indian Ocean Region, 9(1), 69-89. https://doi.org/10.1080/19480881.2013.795014

Rustam, I. (2016). Tantangan ALKI dalam Mewujudkan Cita- cita Indonesia sebagai Poros Maritim Dunia. Indonesian Perspective, 1(1), 1-21. https://doi.org/10.14710/ip.v1i1.10426

Saeed, M. (2017). From the Asia-pacific to the indo-pacific: Expanding sino-U.S. strategic competition. China Quarterly of International Strategic Studies, 3(4), 499-512. https://doi.org/10.1142/S2377740017500324

Saputra, P. N., \& Sudirman, A. (2020). Pengembangan Konsep Indo-Pasifik: Sebuah Konstruksi Geopolitik Indonesia di Kawasan Melalui ASEAN. Jurnal Sosial Politik, 6(2), $214-224$. https://doi.org/10.22219/sospol.v6i2.7254

Scott, D. (2019). Taiwan's Pivot to the Indo-Pacific. Asia-Pacific Review, 26(1), $29-57$. https://doi.org/10.1080/13439006.2019.1618602

Shah, R. (2020). Will the Indo-Pacific strategy besiege China? Australian Journal of Maritime and Ocean Affairs, 12(3), 125-137. https://doi.org/10.1080/18366503.2020.1782806

Simón, L. (2013). Reaching Beyond the Indo-Pacific. Comparative Strategy, 32(4), $331-353$. https://doi.org/10.1080/01495933.2013.821851

Taher, A. (2017). Babak Baru Metode Penelitian Geografi Manusia. Jurnal Sosiologi USK (Media Pemikiran \& Aplikasi), 11(1), 1-22. https://doi.org/10.24815/jsu

Utami, K. W. P., \& Kurniawati, E. (2017). Kepentingan Cina dalam Membangun Military Support Hub di Djibouti. Paradigma, 21(1), 149-200.

Utami, S., Sumertha, I. G., \& Pedrason, R. (2019). Penyusunan Grand Strategy Keamanan Nasional untuk Optimalisasi Kekuatan Nasional Indonesia. Jurnal Damai Dan Resolusi Konflik, 5(3), 19-42.

Vandini, F. I., Pedrason, R., \& Mundayat, A. A. (2018). Peran Diplomasi Pertahanan dalam Menjaga Perbatasan Maritim Indonesia-Malaysia di Kepulauan Riau guna Mencegah Perdagangan Orang. Jurnal Diplomasi Pertahanan, 4(3), 27-46.

Wirth, C. (2018). Whose "Freedom of Navigation"? Australia, China, the United States and the making of order in the "Indo-Pacific." Pacific Review, 32(4), $475-504$. https://doi.org/10.1080/09512748.2018.1515788

Yanuarti, Indri. Wibisono, Makarim. Midhio, \& Wayan. (2020). Strategi Kerja Sama Indo-Pasifik untuk Mendukung Pertahanan Negara: Perspektif Indonesia. Jurnal Strategi Pertahanan Semesta2, 6(1), 41-70.

Yarger, H. R. (2006). Strategic theory for the 21st century: the little book on big strategy. Carlisle, PA: Strategic Studies Institute, U.S. Army War College.

Yunanto, S., \& Samhudi, R. G. (2019). Different Interests Explain Different Proposals: The Contestation of Indo-Pacific Cooperation Framework between ASEAN and the US Sri Yunanto \& Galby Rifqi Samhudi. Global Strategis, 13(2), 1-16. 